DOI: $10.17516 / 1997-1370-0884$

УДК $008+7.03$

\title{
Reflection of the Spiritual World of Nikita Grigorievich Stroganov in Church Art
}

\author{
Semyon D. Voroshin* \\ South Ural State University \\ Chelyabinsk, Russian Federation
}

Received 10.10.2021, received in revised form 10.12.2021, accepted 18.01.2022

\begin{abstract}
In this article the author examines the peculiarities of the personalities of the Stroganovs, entrepreneurs and patrons of the arts at the example of the Nikita Grigorevich. The main pivotal concepts that existed in the culture of the Late Middle Ages are determined, the channels of their transmission in society are indicated. To understand the factors that influenced his worldview and were reflected in the art of the Late Middle Ages, the theory of identity was chosen, which determines the involvement of a person in certain areas of culture at universal, national and regional level. This phenomenon is realized through the adoption of fundamental values characteristic of society. The translators of these values and cultural codes in Russia during the late Middle Ages were the church, chronicles and books, public and family institutions and art. The latter is able to convey semantic concepts through a system of images and symbols filled with emotions and forming a person's involvement with the themes and ideas of the works. The author describes the influence of the fundamental ideas of that time on the formation N. G. Stroganov's spiritual world. It's identified cultural codes that shape the personality of entrepreneur and found their manifestation in the art he revered.
\end{abstract}

Keywords: russian art of the 16th-17th centuries, the Stroganovs, ktitor activities, art patronage, formation of cultural identity, cultural codes of Russia in the late Middle.

Research area: culturology.

Citation: Voroshin, S.D. (2022). Reflection of the spiritual world of Nikita Grigorievich Stroganov in church art. J. Sib. Fed. Univ. Humanit. soc. sci., 15(1), 141-152. DOI: 10.17516/1997-1370-0884

(C) Siberian Federal University. All rights reserved

* Corresponding author E-mail address: akseniya.krupkina@mail.ru 


\title{
Отражение духовного мира \\ Никиты Григорьевича Строганова \\ в церковном искусстве
}

\section{С.Д. Ворошин}

Южно-Уральский государственный университет

Российская Федераџия, Челябинск

\begin{abstract}
Аннотация. В работе исследуются особенности личностей предпринимателей и покровителей искусств Строгановых на примере одного из значимых представителей рода Никиты Григорьевича. Определены основные стержневые концепты, существовавшие в культуре позднего Средневековья, обозначены каналы их трансляции в обществе. Для понимания факторов, повлиявших на его мировоззрение и отразившихся в искусстве указанного периода, была выбрана теория идентичности, определяющая сопричастность человека тем или иным областям культуры и ее мировому, национальному и региональному уровням. Этот феномен реализуется через принятие основополагающих ценностей, характерных для общества. Трансляторами этих ценностей и культурных кодов в России времен позднего Средневековья были церковь, Священное писание, летописи и богослужебные книги, общественные и семейные институты и искусство. Последнее способно передавать смысловые концепты через систему образов и символов, наполненных эмоциями и формирующих у человека сопричастность темам и идеям произведений. Установлен характер влияния основополагающих идей того времени на формирование духовного мира Н.Г. Строганова. Выявлены культурные коды, сформировавшие личность предпринимателя и нашедшие свое проявление в почитаемом и поддерживаемом им искусстве.
\end{abstract}

Ключевые слова: русское искусство XVI-XVII вв., род Строгановых, ктиторская и меценатская деятельность, формирование культурной идентичности, культурные коды России позднего Средневековья.

Научная специальность: 24.00.01 - теория и история культуры.

\section{Введение в проблему исследования}

Понимание и дальнейшая корректировка современных культурных и социальных процессов как локального, так и глобального характера обеспечиваются глубоким анализом схожих явлений в прошлом. Значимую роль в исторических процессах играют личности, оказывавшие наиболее сильное влияние в своих сферах деятельности. И для глубокого осмысления их действий и решений требуется подробное изучение обширных факторов, сформировавших их внутренний мир, а также нашедших свое отражение в поддерживаемом ими искусстве.
Династия Строгановых, промышленников, торговцев и меценатов, внесла значимый вклад в жизнь и культуру людей не только своего региона, но и страны в целом. В научной литературе уже раскрыто множество сфер деятельности Строгановых времени позднего Средневековья (XVI-XVII вв.): ведение хозяйства (Dmitriev, 1895; Vvedenskiy, 1962), архитектура (Braytseva, 1977), храмовое фресковое письмо (Preobrazhenskiy, 2016), написание икон (Dmitriyev, 1955; Parfent'yev, 2004), создание ювелирных изделий и лицевого шитья (Georgiyevskaya-Druzhinina, 1929; Silkin, 1984), производство и коллекцио- 
нирование книжных богатств (Mudrova, 2015; Parfent'yev, 2008), церковная музыка (Parfent'yev, Parfent'yeva, 1994), вклады в церкви и монастыри (Savvaitov, 1886), ктиторская деятельность (Igoshev, 2007; Parfent'yev, Parfent'yeva, 2020). Ряд научных трудов посвящен определению вклада конкретных представителей рода в вышеперечисленные сферы (Kustova, 2016; Musikhin, 2012; Bogdanov, 2017). Как мы видим, вклад династии солепромышленников в формирование экономического и культурного облика своего региона и страны уже достаточно серьезно изучен. Однако на данный момент недостаточно изучена специфика влияния различных условий на конструирование комплекса аспектов идентичности Строгановых в XVI-XVII вв. Для этого нужно определить основные стержневые концепты, существовавшие в культуре позднего Средневековья, и обозначить каналы их трансляции в обществе. Затем следует установить характер влияния основополагающих идей того времени на формирование духовного мира промышленников. Исходя из этого требуется уточнение степени влияния культурной идентичности заказчиков и исполнителей на церковное региональное искусство XVI-XVII вв. Вопрос специфики формирования идентичности Строгановых на данный момент разработан лишь в отношении основателя рода Аники Федоровича Строганова (1497-1570) (Voroshin, 2020). Данная работа направлена на расширение данного аспекта знаний в отношении его внука - Никиты Григорьевича Строганова (15.09.1560-24.11.1616).

\section{Методология исследования}

Выбранная для исследования теория идентичности позволяет обособленно изучить разные аспекты личности. Понимание специфики их взаимосвязей дает возможность глубже понять внутренний мир человека в целом, причины и мотивации его поступков. Важно выявление тех культурных кодов, которые оказывали влияние на историческую личность и ту культуру, которую она создавала в окружающем пространстве.
Феномен идентичности исследуется с XX в. учеными различных гуманитарных областей, включающих психологию, философию, историю, социологию, культурологию и т. д. (Vodop'yan, Khamaganova, 2018; Parfentieva, 2018; Koptseva, Kistova, 2015). Современное понимание требует изучения феномена как единого целого, но с учетом особенностей отдельно взятых аспектов. Составляющие идентичности, находясь между собой в тесной иерархичной связи, характеризуются сопричастностью личности определенным областям культуры. В данном процессе проявляется приобщение человека к основным достижениям региональной, национальной и мировой культуры общества. Это реализуется через трансляцию индивидууму стержневых концептов культуры, формирующих ценности и нормы определенного социума в конкретный период его развития и выражающихся в языке, религии, истории народа, его культурных героях (в том числе местных и общечтимых святых), традициях и т. д. Через них передается определенный культурный код, представляющий собой информацию для потомков, аккумулированную прошлыми поколениями для построения уникального будущего, отличающего один народ от другого. Информация эта закодирована, что также служит задачам идентификации, позволяя отличать представителей разных культур друг от друга. С культурными кодами также связан комплекс стереотипов, опирающихся на коллективное бессознательное. Распространяемая информация может быть скрыта для прямого понимания, но проявляться в поступках и поведенческих реакциях (Gudkov, 2017).

Трансляция этих ценностей в исследуемый период происходит через церковь, летописи, обычаи, фольклор, передачу семейных традиций, произведения церковного искусства и книги (доступ к которым открыт духовенству и образованной элите) (Sukina, 2013: 5). Через эти культурные каналы передаются стержневые концепты, представляющие собой совокупность созидательных идей, существующих в системе и определяющих характерные особенности 
идентичности как отдельной личности, так и общественной группы в целом. Опираясь на такое понимание стержневых концептов, мы сможем выявить вектор и значение деятельности рода Строгановых по развитию социокультурного пространства Русского государства указанного периода.

На формирование особенности поведения как в быту, так и в делах, на духовноценностные принципы Строгановых изначально оказали влияние природные и географические условия. Их предки были люди из земель Русского Севера, поморы, они обладали качествами, позволившими добиваться успеха, с упорством преодолевая многие трудности. Ярким примером успешного промышленника является Аника Федорович Строганов. Он родился в 1497 г., к 18 годам стал владельцем собственного хозяйства в Сольвычегодских землях. Заручался поддержкой центральных, местных властей и церкви, выполнял поручения царского двора и московского митрополита. Аника Федорович заложил Благовещенский собор в Сольвычегодске (1560-1584), ставший домовым храмом для рода Строгановых, в конце жизни принял монашество в Пыскорском монастыре. Помимо обширных владений и щедрых вкладов в храмы Аника Федорович оставил после себя богатую библиотеку в 215 книг (Mudrova, 2015: 91). Таким образом, именно им было основано родовое гнездо для последующих поколений. А.Ф. Строганов заложил фундамент профессиональных качеств и духовных ценностей, послуживших опорой многим его потомкам в торгово-промышленной и меценатской деятельности. Он был наделен знаниями и талантом организовывать дела на очень высоком уровне. Аника Федорович хорошо разбирался в искусстве и архитектуре страны, нанимал лучших мастеров. Вместе они формировали культуру своего региона, создавали произведения по своему духовному и художественному уровню, сопоставимые со столичными работами. Одним из факторов, сформировавших взгляды Аники Строганова, стал мощный образ Ивана Грозного, объединявшего земли и разви- вавшего в стране культуру для будущих поколений. Другим образцом для подражания выступил святой Стефан Пермский, занимавшийся просветительской деятельностью на тех же землях, что и Строгановы, но значительно ранее. Воспринятая из Жития Стефана Пермского идея мирного диалога с народами другой веры и культуры обеспечила Строганову выживание на осваиваемых территориях и успех в торговле. Таким образом, Аника Строганов заложил те идеи, которые потом стали основой мировоззрения многих потомков династии, отразились в поддерживаемом ими искусстве. Будучи сопричастным элите своего времени как в экономическом, так и духовном плане, они поддерживали искусство на высоком уровне мастерства и художественного содержания, соответствовавшего не только задачам церковного служения, но и высоким эстетическим вкусам заказчиков.

Помимо Аники Федоровича, еще одним значимым представителем рода знаменитых промышленников, сформировавших уникальный культурный облик своего региона и внесших весомый вклад в создание особого направления в искусстве русского позднего Средневековья, является Никита Григорьевич Строганов. Для более глубокого понимания его феномена как успешного промышленника, талантливого ктитора и мецената следует определить и проанализировать факторы, сформировавшие личность и духовный мир Н.Г. Строганова, учитывая совокупность общерусских и региональных процессов, проходивших в культуре и обществе во время его жизни. В нашем подходе ключевым в понимании специфики идентичности является ее сложная, многоаспектная иерархичная структура, отражающая сопричастность человека областям мировой, национальной и региональной культуры и вовлеченность личности в их основные процессы. Каждый уровень, несмотря на характерную обособленность, существует в тесной связи с другими. Так, узкая культурная группа является неотъемлемой частью более широкой, испытывая влияние общих про- 
цессов. Эта специфика предполагает многоаспектное изучение личности Никиты Григорьевича: не только как представителя семьи Строгановых и своего сословия, но и в контексте локальных и глобальных социальных, культурных и политических событий, имевших место в России времени позднего Средневековья.

\section{Анализ факторов, \\ сформировавших личность \\ и духовный мир Н. Г. Строганова}

Понимание внутреннего мира ключевых представителей рода основывается прежде всего на исследовании их биографии. Никите Григорьевичу Строганову в довольно молодом возрасте (восемнадцати лет) досталась по наследству треть всех строгановских владений (Mudrova, 2015: 91; Parfent'yev, Parfent'yeva, 1994: 267) в Сольвычегодске, Устюжском уезде, Москве и Калуге, на Урале (Vvedenskiy, 1962: 47-48). Так, большую часть жизни он был владельцем обширных земель и промышленных хозяйств, распоряжался огромными людскими и материальными ресурсами и фамильным богатством. Таким образом, с ранних лет у Никиты Григорьевича формировалось понимание собственной принадлежности к особому, торгово-промышленному сословию, тесно связанному с семейным аспектом идентичности.

Говоря об осознании его семейной принадлежности, стоит прежде всего упомянуть события, произошедшие в первые годы самостоятельной хозяйственной деятельности Никиты Григорьевича. В 1581 г. пермские земли Строгановых были дважды атакованы во время восстания местных племен, с которых Строгановы взимали дань (Mudrova, 2015: 92). Князь народности манси Бегбелий Агтагов со своими людьми 22 июля 1581 г. совершил набег на чусовские городки и Сылвенский острожек, но Строгановы быстро подавили восстание и взяли в плен предводителя захватчиков. Позже, 1 сентября 1581 г., на строгановские владения напал пелымский князь Аблегерим (Shashkov, 2001). Нападение отразили
Семен Аникиевич и Максим Яковлевич Строгановы. При этом орловские вотчины Никиты Григорьевича не подвергались прямой опасности, и он не помог ближайшим родственникам в защите их земель. Семен Аникиевич и Максим Яковлевич подали жалобу правительству, это повлекло грамоту 6 ноября 1581, повелевшую Никите Григорьевичу действовать заодно с родственниками.

Мотивация невмешательства Н.Г. Строганова в дела семьи в научной литературе трактуется по-разному. Одна из версий - это молодость и неопытность Никиты Григорьевича, а также отдаленность его вотчин от набегов (Vvedenskiy, 1962: 95). Как бы ни относился к этому поступку сам Никита Григорьевич на тот момент, он привел к серьезному отчуждению его от семьи, получившему официальный статус вмешательством правительства Ивана Грозного. Грамотой от 16 ноября 1582 г. всем Строгановым предписывается сообща стоять против набегов (Miller et al., 1999: 335-336). Но и в дальнейшем Никита Григорьевич продолжал уклоняться от участия в делах семьи. Поход Ермака в сибирские земли, активно поддерживаемый Строгановыми, обошелся без его существенной помощи. Апогеем отчуждения от семьи стала конфискация у него в 1588 г. правительством царя Федора Иоанновича всей орловской вотчины (Vvedenskiy, 1962: 122). По одному из предположений, это могло быть наказанием за неучастие в организации похода Ермака. Другая версия базируется на мнении, что богатство и обширные владения Строгановых вызывали зависть, недовольство у знати. После смерти Ивана Грозного, благоволившего Строгановым, земское правительство упразднило прежние порядки и лишило всех бывших опричников (а Строгановы входили в опричнину) высоких окладов, выслуженных во время службы Ивану Грозному. Сольвычегодских вотчинников это не коснулось в полной мере, пока те несли все расходы, связанные с завоеванием земель и обороной от набегов местных народов Сибири. А с присоединением Сибири функции, возложенные 
на Строгановых, исчерпали себя (Mudrova, 2015: 92-94).

Вследствие этого в годы опалы солепромышленники не утверждали своего влияния на новых землях, их люди перестали собирать дань по всему Приуралью. Но казна не могла долгое время обходиться без услуг Строгановых, и в 1591 г. царь Федор снова пожаловал Никите Григорьевичу его вотчину (Mudrova, 2015: 93). Если лишение материальных ресурсов, родового наследства и социального статуса могло деструктивно повлиять на молодого Строганова, то их возвращение оказало позитивный эффект на сложную структуру идентичности Никиты Григорьевича. Пребывание в опале в дальнейшем могло стать одним из мотивирующих факторов, побуждавших Н.Г. Строганова принимать активное участие в формировании культуры и церковного искусства родного края.

Возможной причиной негативного отношения со стороны власти к Никите Григорьевичу было то, что он в свое время являлся сторонником князя Ивана Петровича Шуйского, регента при царе Федоре Ивановиче. В политической борьбе с Борисом Годуновым И.П. Шуйский проиграл. Все его сторонники подверглись опале, в том числе, возможно, и Н. Г. Строганов. Опала была непродолжительной - орловская вотчина вернулась к Никите, а грамотой 7 апреля 1597 г. ему пожаловали земли по Каме от реки Ласьвы до реки Ошапа (Vvedenskiy, 1962: 112-113).

Будучи представителем влиятельного финансово-промышленного дома Строгановых, Никита Григорьевич был приобщен к событиям государственной важности. Знакомство с элитой страны, прямое и косвенное участие и неучастие как в распространении влияния на новых землях, так и в политической борьбе сформировали элитарное восприятие как собственной личности, так и всего рода.

Как и основатель рода Аника Федорович, Никита Строганов жил в своих землях в тревожных условиях «осажденной крепости». Однако это не помешало им обоим строить и поддерживать храмы, заниматься покровительством церковного искусства. Оба они стали виднейшими ктиторами - один в период Ивана Грозного, другой позднее, в правление Федора Иоанновича и Бориса Годунова. Первым примером строительства каменного здания в вотчинах Строгановых стал пятиглавый двухстолпный Благовещенский собор в 1560 г., являвшийся их домовой церковью (освящен в 1584 г.). Заложил его основатель рода Аника Федорович, поддерживали и обеспечивали всем необходимым остальные представители рода, в том числе Никита Григорьевич. Церковь стала домовой для всего рода, в нее представители семьи делали вклады, формируя фундамент региональной, православной и семейной идентичности.

Внутреннее убранство собора формировалось в соответствии со вкусом сольвычегодских промышленников, требовавших высокого качества в исполнении. Так, фрески были написаны московскими мастерами Федором Савиным и Стефаном Арефьевым (Preobrazhenskiy, 2016: 14). Наиболее значимые работы пятиярусного иконостаса исполнялись лучшими иконописцами царской Оружейной палаты - Прокопием Чириным, Истомой Савиным, Назарием Истоминым. Внутреннее и внешнее убранство храма соответствует древним московским традициям архитектуры, что следует из общего конструктивного решения, объема полукруглых апсид, членения фасадов, сочетания сурового монолитного, почти лишенного декора внешнего облика с просторным интерьером.

Начало обширного церковного строительства в осваиваемых землях, возведение родового Благовещенского собора, отстройка основанных фамилией монастырей, а также отдельных палат для каждой семьи рода привели к росту числа «иконников» среди дворовых кабальных людей и холопов во владениях Строгановых. Здесь же были наемные мастера-иконописцы, выполнявшие временные подряды. С 1580-х гг. началась деятельность строгановских иконных мастерских, что подтверждается документально. В описании двора Никиты Григо- 
рьевича при хозяйских хоромах упоминаются «чюланы люцкие», расположенные «меж иконною горницею и меж большой избой»; да на заднем дворе - «столовая..., подле нее горница иконная». Среди имущества Максима Яковлевича, двоюродного брата Никиты, хранились «образное гвоздье», «коробья лубяная, в ней всякие образные краски и вохры» (Vvedenskiy, 1924: 23-24,32).

Чтобы проследить, как вкусы и взгляды на искусство заказчиков отразились в поддерживаемом искусстве, следует понять, какие еще факторы сформировали духовный мир и мировоззрение промышленников. Говоря об идентичности представителей Строгановых, уместно предположить, что их «культурным героем», неким образцом для подражания в торговопромышленной и культурной политике становился правящий государь своего времени. Анике Федоровичу должны были быть близки взгляды такой сильной личности, как Иван Грозный, объединявший земли силой и закладывавший фундамент национальной культуры для следующих поколений. Основателю рода промышленников нужно было выработать принципы ведения торгово-промышленных дел и ктиторской деятельности, но основной задачей было сформировать мощную материальную базу. У Никиты Григорьевича эта потребность не стояла так остро. Можно предположить, что ему больше близок образ сына Ивана IV Федора, значительно более мягкого в своей политике. Нечто схожее наблюдалось и в характере Никиты Григорьевича, его подходе в ведении дел. Поведение во время конфликтов не показывает его как воина или защитника, способного на решительные, самоотверженные действия. Однако впоследствии именно при Никите Григорьевиче наблюдается расцвет художественных мастерских, формируется мощная «строгановская» школа иконописи. Он обладал очень тонким вкусом, отдавал предпочтения изяществу и мелочности письма в почитаемой иконописи. Характерным примером служит икона «Никита-Воин, предстоя- щий Богоматери с Младенцем, с житием в 20-ти клеймах», изображающая святого, соименного Никите Григорьевичу (рис. 1).

Впоследствии она стал вкладом Никиты в домовой Благовещенский собор (Trubacheva, 2003: 40). Существовали и другие иконы с изображением этого святого во владении Строгановых: «Никита Великомученик, предстоящий Богоматери с Младенцем» (рис. 2), предположительно из сольвычегодского Благовещенского собора и «Складень трехстворчатый, с изображением Никиты Воина в среднике и жития святого на створках» (рис. 3). Последняя была за авторством Прокопия Чирина, предположительно из Сольвычегодского собора, и на обороте содержала информацию о том, что украшена икона была по заказу Никиты Григорьевича (Trubacheva, 2003: 52). Можно предположить, что изображаемый святой не только тезоименный сольвычегодскому промышленнику, но и наделен его внешними чертами. Его облик не соответствует воину, он тонок и изящен, что гораздо ближе эстетическим вкусам ценителя искусства Никиты Григорьевича.

Ведя торгово-промышленную деятельность во многих городах и местностях страны, Никита Григорьевич был знаком с выдающимися образцами искусства и архитектуры. Другим источником образованности, культурного кругозора и транслятором ценностей в эпоху позднего Средневековья были книжные собрания. Таким образом, мощной базой, сформировавшей духовный мир и эстетические идеалы Никиты Григорьевича Строганова, стала его библиотека. После раздела семейного фонда ему достались 73 книги (Mudrova, 2015: 95). В течение жизни он приумножил это собрание, о чем свидетельствует посмертная опись, насчитывающая 359 книг (Mudrova, 2015: 97). По большей части это литература для богослужения, помимо нее зафиксированы толковые книги, сочинения святых отцов, жития святых, произведения нравоучительного, дидактического и панегирического характера. Немало произведений собрания были посвящены государственному, общественному и церковному 


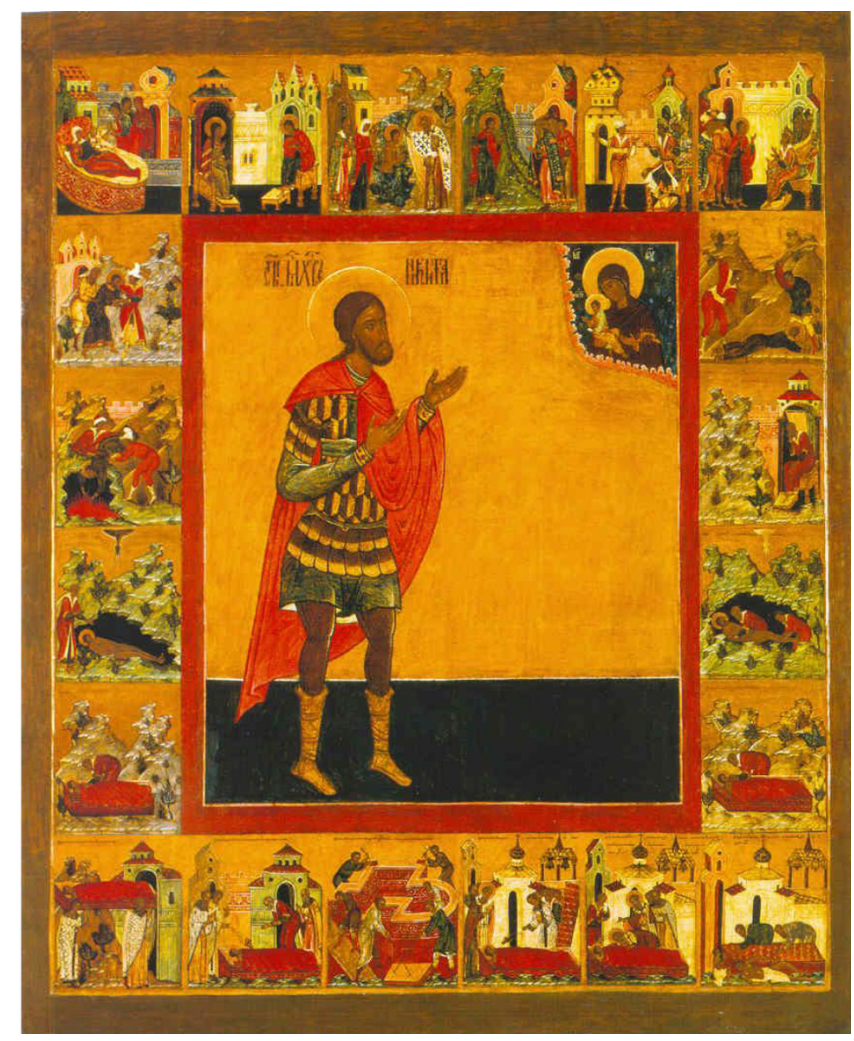

Рис. 1. Никита-Воин, предстоящий Богоматери с Младенцем, с житием в 20-ти клеймах. Конец XVI в. Сольвычегодский историко-художественный музей

Fig. 1. Nikita Warrior Image. End of the XVI century. Historical and Art Museum in Solvychegodsk

устройству России, присутствуют книги и рукописи юридического, исторического, географического и энциклопедического характера (Mudrova, 2015: 104-105).

В собрании Никиты Григорьевича имелись переводные литературные произведения («Александр Македонский», «Книжка о Цареграде», «Книга письменная Троя»), русские повести (Mudrova, 2015: 105-106), учебная литература по грамматике и арифметике (Mudrova, 2015: 107). Такое собрание говорит об обширной и глубокой образованности Никиты Григорьевича, широком кругозоре его интересов, охватывающих не только региональный, но и общероссийский и мировой уровни культуры. В собрании и вкладах Н.Г. Строганова содержались книги, отражавшие его интерес к проблемам политического, церковного устройства, идеологической борьбы и истории отечества.
Среди представителей рода Никита Григорьевич был одним из самых ярых собирателей книг, многие из которых жертвовал в храмы. Так, в Благовещенский собор им было вложено 109 книг и еще 6 вместе с дядей Семеном и двоюродным братом Максимом. Для примера, его дед Аника Федорович вложил в тот храм 16 книг, а отец в совокупности с братьями Яковом и Семеном - 17 (Mudrova, 2015: 116). В этом прослеживается его трепетная забота о развитии церковного искусства Сольвычегодска. Большое число отданных богослужебных и певческих книг обеспечили высокий уровень службы и хорового пения. Если Аника Федорович основал строительство Благовещенского собора, то его внук Никита Григорьевич, судя по всему, стремился заложить интеллектуальную базу храма через библиотечный фонд, который не только 
включал требуемый набор книг для службы, но и являлся пополняемой основой знаний по множеству вопросов истории и культуры общества. Образцом для подражания в устройстве и наполнении семейного Благовещенского собора выступали лучшие храмы Москвы. В этом стремлении не уступать столичному уровню Никита Григорьевич собрал одну из самых крупных личных библиотек конца XVI - начала XVII в. Еe состав позволяет судить о мировоззрении, читательских вкусах и культурных потребностях одного из значимых представителей Строгановых.

\section{Заключение}

Итак, представители рода Строгановых оказали большое влияние на формирование культуры родного края. Аника Федорович заложил мощный материальный и духовный фундамент, богатство которого приумножали его потомки. Перед его внуком, Никитой Григорьевичем, уже стояла задача не сформировать основы профессиональных навыков, духовных ценностей для торгово-промышленной и ктиторской деятельности рода, а развивать и углублять эти направления дальше. Никита Григорьевич в своих владениях организовывает мастерские церковного искусства, именно под его руководством создаются изящные шедевры иконописи XVI-XVII вв. В этом ему помогает особый подход, свойственный как Анике Федоровичу, так и большинству успешных представителей рода и в промышленности, и в поддержке искусства, а именно в умении организовывать дело на самом высоком уровне при участии выдающихся мастеров своего времени. Обширная библиотека Никиты Григорьевича, основа которой досталась от деда, сформировала взгляды и вкусы владельца и была приумножена. Она стала одной из самых богатых личных собраний своего времени. В ней нашел отражение разносторонний кругозор Никиты Григорьевича, стремившегося собрать фундаментальный фонд знаний об истории прошлого и достижениях наук своего времени. Благодаря многочисленным

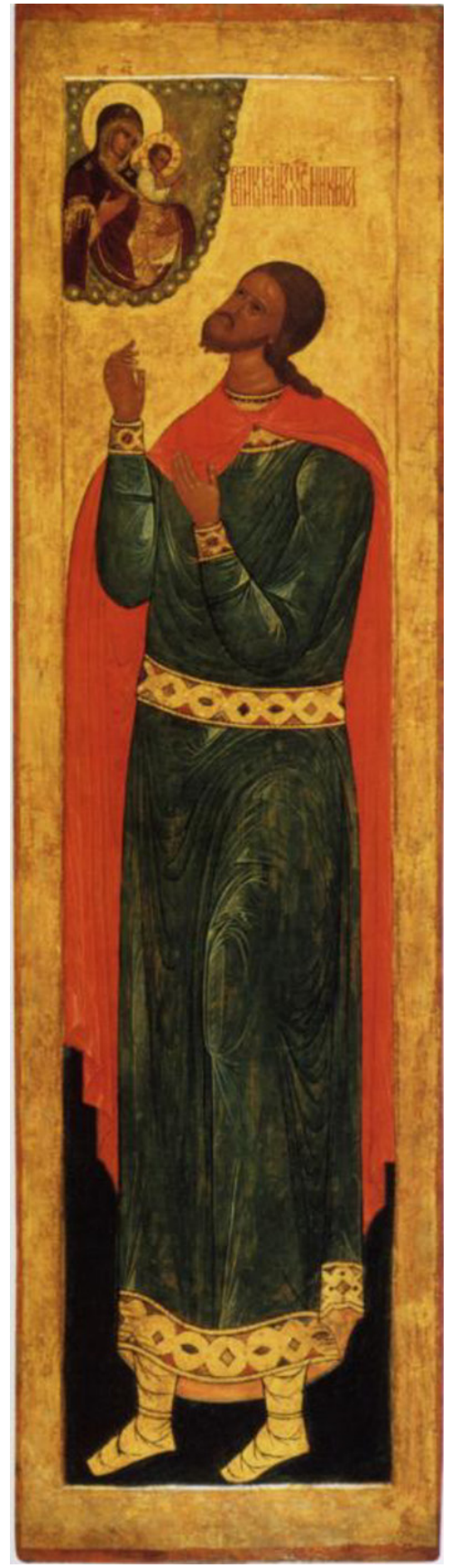

Рис. 2. Никита Великомученик, предстоящий Богоматери с Младенцем. Начало XVII в. Сольвычегодский историко-художественный музей

Fig. 2. Nikita Great Martyr. The beginning of the XVII century. Historical and Art Museum in Solvychegodsk 


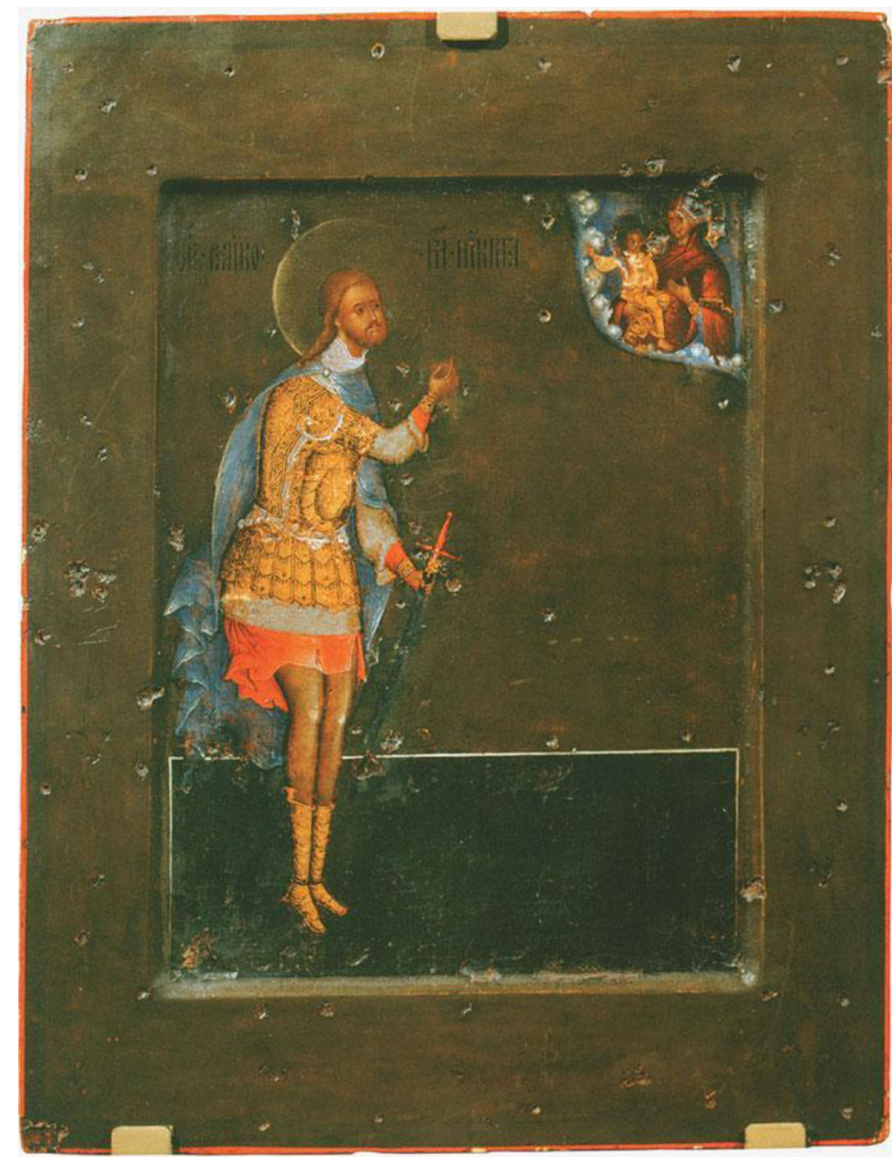

Рис. 3. Изображение Никиты Воина в среднике трехстворчатого складня. Прокопий Чирин. 1593 г. Государственная Третьяковская галерея

Fig. 3. Nikita Warrior Image. Prokopii Chirin. 1593. State Tretyakov Gallery

вкладам в Благовещенский собор книг как церковного, так и светского характера, фамильный храм превратился в центр не только церковного искусства, но и мощного культурного наследия. Образцом Никите Григорьевичу была столичная культура - оттуда он нанимал мастеров, состав библиотеки ориентировался на собрания крупнейших московских храмов. Однако следование московским образцам было осуществлено на высоком уровне реализации, а само содержание поддерживаемого искусства было особым, отвечая особенностям вкуса, духовного мира и сложившейся идентичности Никиты Григорьевича Строганова.

\section{Список литературы / References}

Bogdanov, V. P. (2017). Status «imenitykh lyudey» Stroganovykh: o chem govoryat zapisi na knigakh [The status of the «eminent people» of the Stroganovs: what the records on the books say]. In Rus', Rossiya. Srednevekov'ye i Novoye vremya [Rus, Russia. Middle Ages and Modern Times], 5. pp. 313-318.

Braytseva O. I. (1977). Stroganovskiye postroyki rubezha XVII-XVIII vv. [Stroganov buildings at the turn of the 17th-18th centuries]. Moscow: Stroyizdat, $175 \mathrm{p}$.

Dmitriev, A.A. (1895). Permskaya starina. [Permian antiquity]. Perm, 6, 215 p. 
Dmitriev, Yu.N. (1955). «Stroganovskaya shkola» zhivopisi [«Stroganov School» of Painting] In Istoriya russkogo iskusstva [History of Russian Art]. Moscow, V.3, 649 p.

Georgiyevskaya-Druzhinina, Ye. V. (1929). Stroganovskoye shit'ye v XVII v [Stroganov sewing in the 17th century]. In Russkoye iskusstvo XVII v. [Russian art of the 17th century]. Leningrad, $188 \mathrm{p}$.

Gudkov, D. B. (2017). Kody kul'tury i sistema yestestvennogo yazyka [Codes of culture and the system of natural language]. In Rusistika bez granits [Russistics without borders], V.1, 1, pp. 43-48.

Igoshev, V. V. (2007). Dragotsennaya tserkovnaya utvar' XVI-XVII vv. lokalizatsiya proizvedeniy Velikogo Novgoroda, Yaroslavlya, Sol'vychegodska [Precious church utensils of the 16th -17 th centuries. localization of works of Veliky Novgorod, Yaroslavl, Solvychegodsk]. Moscow, 545 p.

Koptseva, N. P., Kistova, A. V. (2015). Konstruirovaniye etnokul'turnoy i obshchenatsional'noy identichnosti kak filosofskaya problema [Construction of ethnocultural and national identity as a philosophical problem]. In Filosofiya i kul'tura [Philosophy and Culture], 1, pp. 12-19.

Kustova, E. V. (2016). Stroganovy i monastyrskoye stroitel'stvo v Priural'ye v seredine XVI-XVII vv [Stroganovs and monastic construction in the Urals in the middle of the XVI-XVII centuries]. In Vestnik Tomskogo. gosudarstvennogo univtrsiteta [Tomsk State University Journal], 402, pp. 71-78.

Miller, G.F. et al. (1999). Istoriya Sibiri [History of Siberia]. In Izdatel'skaya firma «Vostochnaya litra» RAN [Publishing company «Vostochnaya Lit-ra»RAS]. V. 1. pp. 335-336.

Mudrova, N.A. (2015). Biblioteka Stroganovykh (vtoraya polovina XVI - nachalo XVIII v.). [Library of the Stroganovs (second half of the 16th - early 18th centuries)]. Yekaterinburg: Ural Branch of the Russian Academy of Sciences, $540 \mathrm{p}$.

Musikhin, A. L. (2012). Rod Stroganovykh po zapisyam nizhegorodskikh i vyatskikh sinodikov [The Stroganov family according to the records of the Nizhny Novgorod and Vyatka synodiks]. In Vestnik NNGU [Bulletin of the UNN], 6 (3), pp. 88-94.

Parfent'yev, N.P. (2004). Stroganovskaya ikona XVI-XVII vv. [Stroganov icon of the 16th -17 th centuries] In Traditsii i novatsii $v$ otechestvennoy dukhovnoy kul'ture: [Traditions and innovations in the domestic spiritual culture]. Chelyabinsk: SUSU, pp. 5-10.

Parfent'yev N. P. (2008). O stroganovskoy masterskoy knizhno-rukopisnogo iskusstva XVI-XVII vv [About the Stroganov workshop of book and manuscript art of the 16th-17th centuries]. In Vestnik YUUrGU. Seriya: Sotsial'no-gumanitarnyye nauki [Bulletin of SUSU. Series: Social Sciences and Humanities], 6 (106), pp. 43-61.

Parfent'yev, N.P., Parfent'yeva, N.V. (1994) Usol'skaya (Stroganovskaya) shkola v russkoy muzyke XVI-XVII vekov. [About the Stroganov workshop of book and manuscript art of the 16th-17th centuries]. Chelyabinsk, $346 \mathrm{p}$.

Parfentieva, N. V. (2018) To the study of reflection of cultural identity processes in the Russian art of the 16-17th centuries. Journal of Siberian Federal University. Humanities \& Social Sciences, 7, pp. 1127-1136.

Parfentieva, N.V., Parfentiev N.P. (2020). The development of arts in the context of the Stroganovs' activity as ktitors and art patrons in the 16th-17th centuries. Journal of Siberian Federal University. Humanities \& Social Sciences, 13(6), pp. 924-944.

Preobrazhenskiy, A.S. (2016). Rospisi Blagoveshchenskogo sobora v Sol'vychegodske [Murals of the Annunciation Cathedral in Solvychegodsk] In Materialy konferentsii «Problemy izucheniya drevnerusskogo i vizantiyskogo iskusstva» [Materials of the conference «Problems of Studying Old Russian and Byzantine Art]. Moscow, $96 \mathrm{p}$.

Savvaitov P. I. (1886). Stroganovskiye vklady v Col'vychegodskiy Blagoveshchenskiy sobor [Stroganov's contributions to the Solvychegodsky Annunciation Cathedral]. In Pamyatniki drevney pis'mennosti $i$ iskusstva. [Monuments of ancient writing and art], Sankt-Petersburg, 61, $119 \mathrm{p}$.

Shashkov, A. T. (2001). Nachalo prisoyedineniya Sibiri [The beginning of Siberia's accession] In Problemy istorii Rossii. Vyp. 4: Yevraziyskoye pogranich'ye. [Problems of the history of Russia. Issue 4: Eurasian borderlands], 2001, pp. 27-28.

Silkin A.V. (1984). Stroganovskoye dvustoronneye litsevoye shit'ye [Stroganov double-sided facial sewing]. In Voprosy issledovaniya, konservatsii i restavratsii proizvedeniy iskusstva [Issues of research, conservation and restoration of works of art]. Moscow, pp. 42-43. 
Sukina, L. B. (2013). Russkoye religioznoye soznaniye vtoroy poloviny XVI-XVII veka: kompleksnoye istochnikovedcheskoye issledovaniye [Russian religious consciousness of the second half of the 16th-17th centuries: a comprehensive study of source studies]. Moscow, $40 \mathrm{p}$

Trubacheva, M.S. (2003). Ikony Stroganovskikh votchin XVI-XVII vekov. Po materialam restavratsionnykh rabot VKHNRTS imeni akademika I.E. Grabarya: Katalog-al'bom [Icons of the Stroganov estates of the 16th-17th centuries. Based on the materials of the restoration work of the All-Union Scientific and Research Center named after academician I. Grabar: Catalog-album], Moscow: Skanrus, 440 p.

Vodop'yan, V.G., Khamaganova, K.V. (2018) Vizual'nyye kody kul'turnoy identichnosti v sovremennom mediaprostranstve [Visual codes of cultural identity in modern media space]. In Vestnik Tomskogo gosudarstvennogo universiteta Kul'turologiya i iskusstvovedeniye [Tomsk State University Journal: Culturology and art history], 32, pp. 229-235.

Voroshin S.D. (2020). Anika Stroganov i russkoye regional'noye iskusstvo XVI v [Anika Stroganov and Russian regional art of the 16th century]. In Vestnik YuURgU: Sotsial'no-gumanitarnyye nauki [Bulliten SUSU: Social and humanitarian sciences], V. 20, 4, pp. 66-71.

Vvedenskiy A. A. (1924). Torgovyy dom XVI-XVII vv. [Trading house XVI-XVII centuries], Leningrad., 1924, $182 \mathrm{p}$.

Vvedenskiy, A.A. (1962) Dom Stroganovykh v XVI-XVII vv. [House of the Stroganovs in the 16th-17th centuries]. Moscow, $307 \mathrm{p}$. 